\title{
A BP Artificial Neural Network Model for Earthquake Magnitude Prediction in Himalayas, India
}

\author{
S. Narayanakumar ${ }^{1}$, K. Raja ${ }^{2}$ \\ ${ }^{1}$ Department of CSE, University College of Engineering, Ramanathapuram, Tamilnadu, India \\ ${ }^{2}$ Department of Mechanical Engineering, University College of Engineering, Dindigul, Tamilnadu, India \\ Email: *narayanakumar82@gmail.com,rajagce@gmail.com
}

How to cite this paper: Narayanakumar, $\mathrm{S}$. and Raja, K. (2016) A BP Artificial Neural Network Model for Earthquake Magnitude Prediction in Himalayas, India. Circuits and Systems, 7, 3456-3468.

http://dx.doi.org/10.4236/cs.2016.711294

Received: May 18, 2016

Accepted: May 26, 2016

Published: September 6, 2016

Copyright $\odot 2016$ by authors and Scientific Research Publishing Inc. This work is licensed under the Creative Commons Attribution International License (CC BY 4.0).

http://creativecommons.org/licenses/by/4.0/

\begin{abstract}
The aim of this study is to evaluate the performance of BP neural network techniques in predicting earthquakes occurring in the region of Himalayan belt (with the use of different types of input data). These parameters are extracted from Himalayan Earthquake catalogue comprised of all minor, major events and their aftershock sequences in the Himalayan basin for the past 128 years from 1887 to 2015. This data warehouse contains event data, event time with seconds, latitude, longitude, depth, standard deviation and magnitude. These field data are converted into eight mathematically computed parameters known as seismicity indicators. These seismicity indicators have been used to train the BP Neural Network for better decision making and predicting the magnitude of the pre-defined future time period. These mathematically computed indicators considered are the clustered based on every events above 2.5 magnitude, total number of events from past years to 2014, frequencymagnitude distribution b-values, Gutenberg-Richter inverse power law curve for the $n$ events, the rate of square root of seismic energy released during the $n$ events, energy released from the event, the mean square deviation about the regression line based on the Gutenberg-Richer inverse power law for the $\mathrm{n}$ events, coefficient of variation of mean time and average value of the magnitude for last $n$ events. We propose a three-layer feed forward BP neural network model to identify factors, with the actual occurrence of the earthquake magnitude $M$ and other seven mathematically computed parameters seismicity indicators as input and target vectors in Himalayan basin area. We infer through comparing curve as observed from seismometer in Himalayan Earthquake catalogue comprised of all events above magnitude $2.5 \mathrm{mg}$, their aftershock sequences in the Himalayan basin of year 2015 and BP neural network predicting earthquakes in 2015. The model yields good prediction result for the
\end{abstract}


earthquakes of magnitude between 4.0 and 6.0.

\section{Keywords}

Artificial Neural Networks, Back Propagation, Multilayer Neural Network, Earthquakes, Prediction Systems

\section{Introduction}

Earthquakes (EQ) are one of the most destructive costly natural hazards faced by the nation in which they occur without an explicit warning and may cause serious injuries or loss of human lives as a result of damages and destroy a lot of properties and buildings or other rigid structures. The prediction of earthquakes remains one of the considerable importances for humanity and most frustrating issues in the Earth Sciences and independent forms of evidence may have been cited to predict the occurrence of major seismic events.

During the past several years a number of earthquake prediction researches were successfully implemented in the way of Theoretical, Mathematical, Computational and Statistical techniques. Recently, the authors presented a review of Earthquake prediction with various optimization techniques [1].

Artificial intelligence, Artificial Neural Network, Fuzzy logic and expert systems have been increasingly used in various applications in the last 30 years: Engineering design, Image recognition [2]; Prediction, Estimation, Pattern recognition, and optimization [3]; Petroleum exploration and production; civil engineering, environmental and water resources engineering, traffic engineering, highway engineering, geotechnical engineering [4]; Image classification [5]; Fingerprint analysis [6]; Software defect prediction [7]; Breast cancer identification [8]; Human action recognition, video surveillance to health-care [9]; Video retrieval [10]; Localization scheme of wireless sensor networks, military surveillance, environmental monitoring, robotics, domestics, animal tracking [11]; Image recognition of plant diseases [12]; Wind power forecasting [13]; Design and analysis of antennas [14]; Image recognition [15]; Multimodal medical image fusion [16]; Satellite data and GPS [17]; water resources engineering [18]; air traffic control [19]; financial forecasting [20]; earthquake prediction [21]-[23].

\section{Study Area}

The collision between India and Eurasia around $50 \mathrm{Ma}$ ago along the Indus-Tsangpo Suture Zone has subsequently resulted into the uplift of the Himalaya, the highest mountain belt in the world. The uplift has produced linear zones of deformation and resulted into crustal shortening along major regional boundary faults. These faults, from north to south known as the Main Central Thrust (MCT), Main Boundary Thrust (MBT) and the Himalayan Frontal Thrust (HFT) as a result large magnitude paleoearthquakes have been reported due to the reactivation of some of these thrusts [24]. 
Himalayas consists of a complete sequence of Paleozonic, Mesozonic and Tertiary rocks, it is considered on the seismically very active regions of the world. The Himalayan evolved as a consequence of collision and convergence of Indian plate with Tibetan plate and Burmese and Chinese plates also. The entire Himalayan belt is in the state of persistent compression due to continued convergence at a rate of $\sim 50 \mathrm{~mm} / \mathrm{yr}$ [25]. A part of this strain is accommodated in the form of recurrent seismic activity. The high level seismic activity is manifested by several major earthquakes during past century. Three great earthquakes ( $M>8$ on Richter scale) have struck the Himalayan region, e.g. 1905-Kangra earthquake, 1934-Bihar-Nepal earthquake, 1950-Assam earthquake, 2015 Kathmandu and were mostly confined to the Main Boundary Thrust and Himalayan Frontal Thrust zone of Himalaya. The spatial distribution of the earthquakes suggests that seismic activity is related to the tectonic framework of the region. Earthquake tremors have been monitored in Himalayan region and recorded Earthquakes, for various spatio-temporal mapping have been found subject to regional tectonics settings reported and major earthquakes recorded during 1505-2015.

\section{Earthquake Data Analysis}

\subsection{Earthquake Data Sources and Acquisition Methodology}

This region is characterized of high seismicity with intensity of 9 to 10 magnitude, or even more. The source catalogs for the database of our study have been compiled from several sources. The earthquake for the time period from 1887 to 2015 collected from the Global Hypocenter Database prepared by USGS (United States Geological Survey). Ten available catalogues (Data, Time, Latitude, Longitude, Depth, Maximum Magnitude, Minimum Magnitude, Standard Deviation, Number of Fields and regions). The PDE (preliminary determination of epicenters) data and IMD (Indian Meteorological Department)—Seismology Division data, for the time period from 1983 to 2015 are also used to update the database. The final catalogue consists of about 462 earthquakes [2013-2015] recorded in Himalayan regions. Magnitude range above the threshold ranges $\mathrm{Mc} \sim 2.5$. Largest earthquakes $\left(\mathrm{M}_{s} \geq 8.0\right)$ occur in the subduction zones and continental thrust zones. All earthquake magnitudes should be in the same magnitude scale and a specific time period. This database offers the opportunity to study the temporal and spatial occurrence of earthquakes.

\subsection{Data Analysis and Computed Parameters}

To carry out the magnitude prediction in the study area, the data source catalog collected during 2013-2016 through an annual. Studying the seismic activity of the world has been done extensively, several researches calculated different parameters of seismicity by using various methods. The empirical relationship between magnitude, frequency and energy of earthquake occurrences is well known as the Gutenberg-Richter (G-R) relationships. The historical earthquake catalog for the study area are divided into a number of pre-undefined time period such as every two events and its time difference between two events, events based on magnitude above 2.5, the input to the 
neural networks are eight computational parameters called seismicity input vectors. The Computational input vector parameters based on Gutenberg-Richter [26].

\section{b-value}

Since Gutenberg and Richter (1944) [27] estimated the parameters a and b, the evaluation of the parameters have been frequently used in statistical calculation of seismicity. The parameter depends on the seismicity rate which varies greatly from regions to regions. The parameter $\mathrm{b}$ is related to properties of focal material and represents tectonic characteristics of a region The $\mathbf{b}$-value is a measure of the relative number of small to large earthquakes that occur in a given area in a given time period. Many researchers estimated the $\mathbf{b}$-value in the intraplate regions, locally, regionally and globally. The low $\mathbf{b}$-value is a characteristic feature of the intraplate regions, except Asia, b-value changes from 0.90 to 2.1 at a corner magnitude Mc of 6.0 to 7.0. In particular, the b-value is the slope of the frequency-magnitude distribution [26]; for the population of earthquakes. Which is the slope of the earthquake recurrence curve 0.69 in the Himalayas collision zone [28] [29]. The $\mathbf{b}$-value determined in this study was calculated using the ZMAP algorithm [30]. Maximum-likelihood b-value were computed using the following equation

$$
b=\frac{1}{M_{\text {mean }}-M_{\text {min }}} \log e
$$

where Equation (1) provides the $M_{\text {mean }}$ is the mean magnitude and $M_{\text {min }}$ the minimum magnitude of the given sample. The frequency-magnitude distribution [27] derives from the power-law relationship between the frequency of occurrence and the magnitude of earthquake (FMD), in the form:

$$
\log N=-b M
$$

For a certain region and time interval, Equation (2) provides the cumulative number of earthquakes $(N)$ having magnitude larger than $M$ where $\mathbf{a}$ and $\mathbf{b}$ are positive, real constants. The parameter a describes the seismic activity Himalayan region $\mathrm{a}=\mathbf{6 . 1 7}$ [28]. It is determined by the event rate and for a certain regions depends upon the volume and time window considered [31].

$M_{\text {mean }}$ : The average magnitude of the last two events $\left(M_{\text {mean }}\right)$

\section{Energy $E$}

Most calculations of the magnitude-energy relation depend directly or indirectly on the Equation (3) for a wave group from a point source [26], ( $E$ in ergs)

$$
\log E=5.8+2.4 m
$$

where: $m$ magnitude Richter scale value.

\section{Energy $J$}

Seismic wave energy $J$ (Markus bath \& Hugo Benioff, 1958), The energy $J$ (ergs) has been computed from the magnitude $\mathrm{M}$ from the Equation (4)

$$
\log _{10} J=9+1.8 M
$$

SD-Standard Deviation from seismic station. 
C-The coefficient of variation of the meant time $\sigma / \mu$ where $\sigma-\mathrm{SD} / M_{\text {mean }}$ and $\mu-$ Mean Time in days (time period between two events).

$\eta$-Mean square deviation $\left(\sigma^{2} / n\right)$ where $\mathrm{n}$-Number of earthquakes above $M_{\text {mean }}$ between two events.

Soft computing techniques are used $\mathrm{n}$ order to reduce the aforementioned computational cost. In this work the application of Artificial Neural Networks (ANNs) is used for training and earthquake magnitude prediction in future also ANN is then used to predict future values due to different sets of random variables.

\section{The multi-layer BP network design issues to be considered}

Making the BP network design should be considered with the number of layers, the number of neurons in each layers of the network, the initial value and learning rate aspects.

1) The number of layers of the network

It has been proved that a Multi-layer BP network can achieved. Maximum number of layers can further reduce errors can improve accuracy but increasing training time, and reduction of error. Maximum number of neurons of the hidden layer, training is easier.

2) The number of hidden layer neurons

To improve the accuracy need maximum hidden layer and output layers with linear activation function.

3) The selection of the initial value of the right value

The back Back propagation network is a very powerful tool for constructing non- linear transfer function between several continuous valued inputs and the one or more continuous valued output.

4) Learning rate

A suitable learning rate for each specific network is present, but for more complex networks, the different parts of the error complex networks. In order to reduce training times to find the learning rate and training time.

5) The expected error select

The expected error value is obtained by comparing the minima, the hidden layer nodes. As a comparison of two different expected error of the network is trained, hidden layer of the neural network to achieve any continuous function approximation.

\section{Modeling}

\subsection{The Back-Propagation Learning Algorithm}

A multi-layer perceptron is a feed-forward neural network (ANN), consisting of a number of neurons linked together and attempts to create a desired relation in an input/ output set of learning patterns. A neural network consists of an input vector layers, more hidden layers and output vector layers. Each layer has its corresponding neurons weight connects. A single training pattern is an Equations (5)-(7) I/O vector of pairs of input-output values in the entire matrix of I/O training set. The neural network model is shown in Figure 1. 


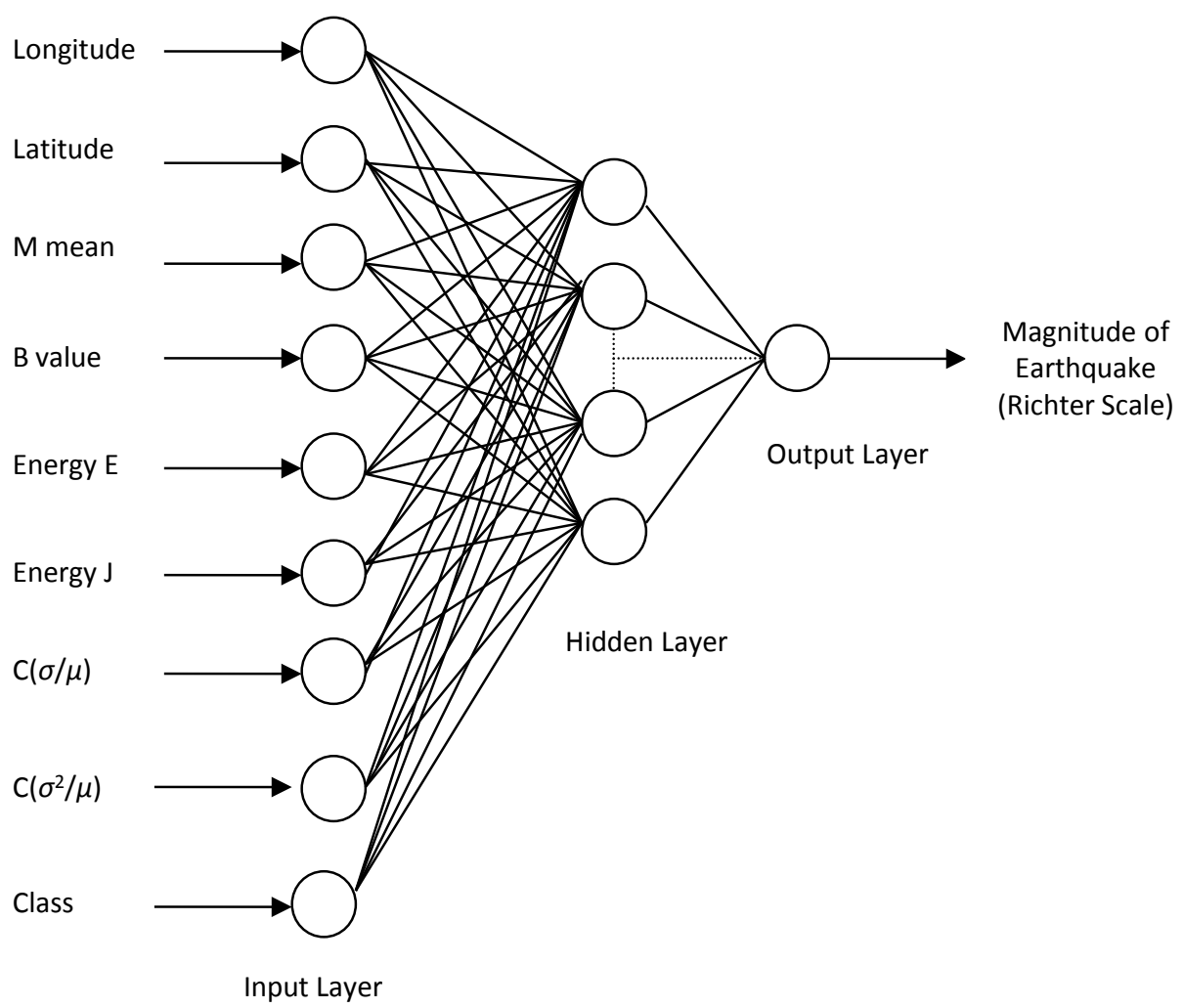

Figure 1. Neural network architecture that was used in modeling magnitude of earthquake.

The input $x_{i}, i=1,2, \cdots, n$ which are received by the input layer are analogous to the electrical signal received by neurons in human brain. In the simplest model these input signals are multiplied by connection weights $w_{p, i j}$ and the effective input net $t_{p, j}$ to neurons is the weighted sum of the inputs

$$
n e t_{p, j}=\sum_{i=1}^{n} w_{p, i j} n e t_{q, i}
$$

where $w_{p, i j}$ is the connecting weight of the layer $\mathrm{p}$ from the $I$ neuron in the $q$ (source) layer to the $j$ neuron in the $p$ (target) layer, $n e t_{q, j}$ is the output produced at the $i$ neuron of the layer $q$ and net $_{q, j}$ is the output produced at the $j$ neuron in the layer $p$. Inputs $x_{i}$ correspond to net $_{q, j}$ for the input layer.

At the output layer the computed output(s), otherwise known as the observed output(s), are subtracted from the desired or target output(s) to give the error signal.

$$
\begin{aligned}
& \varepsilon(w)=\frac{1}{2 m}\|E(w)\|^{2} \\
& E_{i}(w)=\sum_{j=1}^{t}\left[\text { out }_{k, j}-\text { tar }_{k, j}\right]
\end{aligned}
$$

where $m$ is the number of training pairs, tark, $I$ and out $k, I$ are the target and the observed output(s) for the node $I$ in the output layer $k$, respectively. This type of ANN training is called supervised learning.

A learning algorithm tries to determine the weights, in order to achieve the right response for each input vector applied to the network. The numerical minimization algo- 
rithms used for the training generate a sequence of weights matrices through an iterative procedure. To apply an algorithmic operation $A$. a starting value of the weight matrix $w(0)$ Equation (8) is needed, while the iteration formula can be written as follows:

$$
w^{(t+1)}=A\left(w^{(t)}\right)=w^{(t)}+\Delta w^{(t)}
$$

All numerical methods applied in ANNs are based on the above formula. The changing part of the algorithm is further decomposed into two parts as Equation (9)

$$
\Delta w^{(t)}=a_{t} d^{(t)}
$$

where $d^{(t)}$ is a desired search direction of the move and at the step size in that direction.

The training methods can be divided into two categories. Algorithms that use global knowledge of the state of the entire network, such as the direction of the overall weight update vector, which are referred to as global techniques. In contrast local adaptation strategies are based on weight specific information only such as the temporal behavior of the partial derivative of the weight. The local approach is more closely related to the ANN concept of distributed processing in which computations can be made independent to each other. Furthermore, it appears that for many applications local strategies achieve faster and reliable prediction than global techniques despite the fact that they use less information [32].

\subsection{Example Application}

As an example, the ANN attempted to predict the next magnitude's intensity ranges from 4 and above in Himalayan regions and number of days for remains for next events. Himalayan region is defined by the working group on Himalaya Earthquake probabilities as an area between geographic coordinates $20.5 \mathrm{~N}$ to $47.6 \mathrm{~N}$ latitudes and 54E to 97.07E longitudes. Historical seismic data recorded in Himalayan region dating back to 1983 is archived by IMD (Indian Meteorological Department)-Seismology Division data, for the time period from 1983 to 2015 are also used to update the database also some data collected form USGS (United States Geological Survey) and is available for free download through the center's website at http://earthquake.usgs.gov/earthquakes/eqarchives/significant/ and Indian Meteorological Department-Seismology Division is used to define input classes and test the BP ANN model developed in this research.

The historical earthquake total $326+135=461$ events magnitude above 2.5 recorded of Himalayan region between $1^{\text {st }}$ January 2013 and $2^{\text {th }}$ December 2015.

The historical earthquake total 326 events magnitude above 2.5 recorded of Himalayan region between $1^{\text {st }}$ January 2013 and $29^{\text {th }}$ December 2014 as shown in Table 2. Fifteen output groups are defined based on upper and lower magnitude levels. First group comprised of earthquake of magnitude less than 3.0, second group comprised of earthquake of magnitude above 3.0 to 3.4 , third group comprised of earthquake of magnitude above 3.4 to 3.8 , fourth group comprised of earthquake of magnitude above 3.8 to 4.2 , fifth group comprised of earthquake of magnitude above 4.2 to 4.6 , sixth group comprised of earthquake of magnitude above 4.6 to 5.0, seventh group com- 
prised of earthquake of magnitude above 5.0 to 5.4, eighth group comprised of earthquake of magnitude above 5.4 to 5.8, ninth group comprised of earthquake of magnitude above 5.8 to 6.2 , tenth group comprised of earthquake of magnitude above 6.2 to 6.6, eleventh group comprised of earthquake of magnitude above 6.6 to 7.0, twelfth group comprised of earthquake of magnitude above 7.0 to 7.4, thirteenth group comprised of earthquake of magnitude above 7.4 to 7.8 , fourteenth group comprised of earthquake of magnitude above 7.8 to 8.2 , fifteenth group comprised of earthquake of magnitude above 8.2 to 8.6 where each group has a magnitude range of 0.4 Richter.

Table 2 shows the Input classes in the training catalogue for the Himalayan regions, the output magnitude range, and number of training data available for each instances [2013-2014] and [2015].

A nine-element vector of seismicity parameters is computed for each time period forming 326 training input vectors (training catalogue/dataset). The training data is divided into nine input classes depending on the magnitude. Input magnitude of the training dataset, the corresponding output classes, the number of training input vector available in each class are shown in Table 1. As explained above. If we want to increase more accurate output Magnitude accuracy rates we have to increase number of years for training, show that we can get more inclusive class values. Therefore it can be concluded from Table 1, the BP ANN is most successive in classifying events into $M<3, M$ = 3.0 - 3.4, $M=3.4-3.8, M=3.8-4.2, M=4.2-4.6, M=4.6-5.0$ and $M=5.0-5.4$ ranges and may not have much success in classifying events into the $M=5.4-5.8, M=$ $6.2-6.6, M=6.6-7.0, M=7.0-7.4, M=7.4-7.8, M=7.8-8.2$ and $M=8.2-8.6$ ranges. The training dataset showing the nine-element input vectors and the corresponding output Magnitude for the event based mean values between $1^{\text {st }}$ January 2013 and $29^{\text {th }}$ December 2014 are shown in Table 2.

For testing, the BP ANN is used to predict the earthquake magnitude range of next events. It is mean average values calculated for every two events in between $1^{\text {st }}$ January 2013 and $29^{\text {th }}$ December 2014 time periods by computed nine-computed parameters test input vectors for each time period. BP ANN training is repeated for each input

Table 1. Architecture and training parameters of the proposed BPANN.

\begin{tabular}{cc}
\hline Architecture & 3 \\
Number of Layers & \\
Number of Neuron on the Layers & Input 9, Hidden 12, Output 1 \\
Activation Function & Tan-Sigmoid, Purelin \\
\hline Training Parameters & \\
\hline Learning Rule & Levenberg-Marquardt \\
Adaptive Learning Rate & Initial: 0.01, increase: 1.04, decrease: 0.4 \\
Momentum Constant & 0.94 \\
Sum-Squared Error & 0.004 \\
Epochs & 10000 \\
\hline
\end{tabular}


Table 2. Training data.

\begin{tabular}{cccc}
\hline $\begin{array}{c}\text { Input } \\
\text { Class }\end{array}$ & $\begin{array}{c}\text { Magnitude } \\
\text { Ranges }\end{array}$ & $\begin{array}{c}\text { Number of Training instants } \\
\text { available [2013-2014] }\end{array}$ & $\begin{array}{c}\text { Number of Training instants } \\
\text { available [2015] }\end{array}$ \\
\hline Class 1 & $<3.0$ & 22 & 9 \\
Class 2 & $3.0-3.4$ & 38 & 24 \\
Class 3 & $3.4-3.8$ & 76 & 22 \\
Class 4 & $3.8-4.2$ & 73 & 34 \\
Class 5 & $4.2-4.6$ & 61 & 17 \\
Class 6 & $4.6-5.0$ & 38 & 12 \\
Class 7 & $5.0-5.4$ & 10 & 7 \\
Class 8 & $5.4-5.8$ & 6 & 3 \\
Class 9 & $5.8-6.2$ & 2 & 2 \\
Class 10 & $6.2-6.6$ & 0 & 1 \\
Class 11 & $6.6-7.0$ & 0 & 2 \\
Class 12 & $7.0-7.4$ & 0 & 0 \\
Class 13 & $7.4-7.8$ & 0 & 1 \\
Class 14 & $7.8-8.2$ & 0 & 0 \\
Class 15 & $8.2-8.6$ & 0 & \\
\hline
\end{tabular}

vectors and the magnitude range of classes for 326 time periods. After each test run, the input vector is added to the training dataset. Therefore the number of training input vectors available for the test iteration is 921 and it is increase by one with each iteration thereafter.

\section{Prediction Verification and Result}

\section{Computational and Statistical Analysis}

The computed values of BP ANN trained and predicted values compared with originally seismometer recorded values in Himalayan regions for 2015. Table 3 shows the Error percentage of successful and unsuccessful prediction rations and Figure 2 shows the comparison chart.

The suitability of the network in predicting small, moderate and large earthquakes is discussed in the following paragraphs:

a) Prediction of small earthquake (Magnitude 3 or less). Originally seismometer records the magnitude 3 - 3.4. The BP ANN predicted 2 - 2.2. It is mention the success in percentage $66.66 \%$

b) Prediction of Moderate earthquakes (Magnitude 3 and above but less than 5.8). Seismometer records the magnitude 4 but BP ANN predicted Magnitude $3 \sim 5$ success in percentage $75 \%-125 \%$, Seismometer records the magnitude $4.0 \sim 5.8$ but BP ANN forecasted Magnitude 4.0 - 4.5 it is less than the originally recorded values.

c) Prediction of large earthquakes (Magnitude 5.8 and above). There is no much more 
Table 3. Comparison between computed values of BPANN predicted values and originally recorded values for 2015.

\begin{tabular}{|c|c|c|c|c|}
\hline Input Class & Output Magnitude Ranges & BP ANN Predicted Values for 2015 & Originally Recorded Values in 2015 & Success Rating In\% \\
\hline Class 1 & $<3.0$ & 2 & 3 & $66.66 \%$ \\
\hline Class 2 & $3.0-3.4$ & 4 & 3 & $133 \%$ \\
\hline Class 3 & $3.4-3.8$ & 3.2 & 3.5 & $91.42 \%$ \\
\hline Class 4 & $3.8-4.2$ & 3 & 4.0 & $75.00 \%$ \\
\hline Class 4 & $3.8-4.2$ & 5 & 4.0 & $125 \%$ \\
\hline Class 5 & $4.2-4.6$ & 4.0 & 4.5 & $88.88 \%$ \\
\hline Class 6 & $4.6-5.0$ & 3.8 & 4.7 & $80.85 \%$ \\
\hline Class 7 & $5.0-5.4$ & 5.0 & 5.5 & $90.90 \%$ \\
\hline Class 8 & $5.4-5.8$ & 4.7 & 5.9 & $79.66 \%$ \\
\hline Class 9 & $5.8-6.2$ & 0 & 0 & $0 \%$ \\
\hline Class 10 & $6.2-6.6$ & 0 & 6.35 & $0 \%$ \\
\hline Class 11 & $6.6-7.0$ & 0 & 0 & $0 \%$ \\
\hline Class 12 & $7.0-7.4$ & 0 & 7.25 & $0 \%$ \\
\hline Class 13 & $7.4-7.8$ & 0 & 0 & $0 \%$ \\
\hline Class 14 & $7.8-8.2$ & 0 & 0 & $0 \%$ \\
\hline Class 15 & $8.2-8.6$ & 0 & 0 & $0 \%$ \\
\hline
\end{tabular}

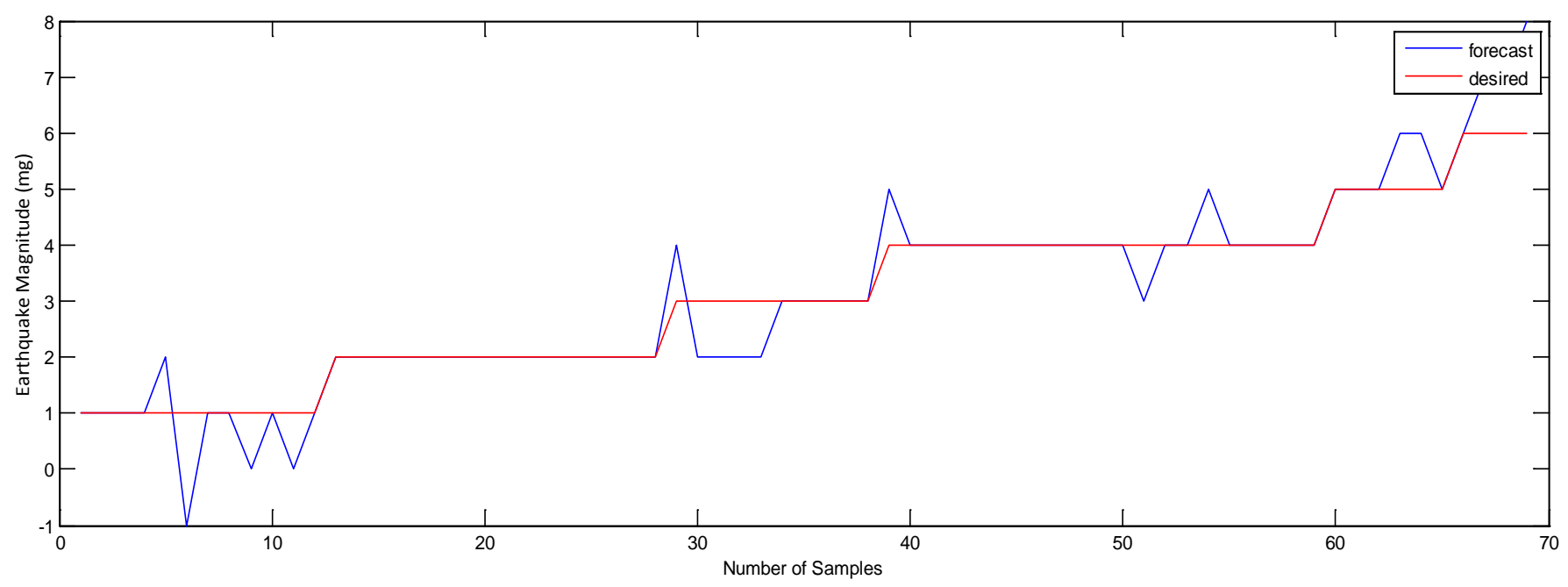

Figure 2. Earthquake prediction and comparison [2013 and 2014 with 2015].

data for training the BP ANN, so that the network cannot produced good results for magnitude above 5.8.

\section{Conclusions}

Earthquake forecasting has become an emerging science; simple earthquake forecasting has been adapted in early ages using simple observations. It is often implicitly assumed 
that "large" earthquakes, which save the peoples life and potential damages, can be forecasted. It would be a major achievement, from a scientific point of view. Earthquake prediction refers to the specification of the expected magnitude, geographic location and time of occurrence of a future event with sufficient precision that the ultimate success of a prediction can be evaluated. We presented a BP Artificial Neural Network which is a very effective model of nonlinear modeling, analysis and predicting earthquake magnitude in the Himalayan region. It has many advantages such as simple learning, memory and self-adaptation, but very complex multidimensional curve, in which multi-local extremism points exist,

The results show that the BP Artificial Neural Network model provides higher prediction accuracy for the Magnitude ranges 3 - 5. BP ANN model is better than the other proposed models for forecasting Earthquakes below Magnitude ranges 5. This is due to the fact that the BP ANN is capable to capture non-linear relationship compared with statistical methods and other proposed methods.

\section{Acknowledgements}

The authors wish to thank the Director, Wadia Institute of Himalayan Geology, Dehradun for providing old and new versions of Himalayan Geology journals; the authors would like to thank two anonymous reviewers for their comprehensive and valuable comments that improved the paper considerable.

\section{References}

[1] Narayanakumar, S., Raja, K., Dhanasekaran, R. and Indradevi, M. (2014) A Review of Application of Intelligent Techniques in Earthquake Prediction. IJEEEAR, 2, 216-219.

[2] Adeli, H. and Hung, S.L. (1995) Machine Learning: Neural Networks, Genetic Algoritms, and Fuzzy Systems. Wiley, New York.

[3] Haykin, S. (1999) Neural Networks: A Comprehensive Foundation. 2nd Edition, PrenticeHall, Englewood Cliffs, NJ.

[4] Adeli, H. and Panakkat, A. (2009) A Probabilistic Neural Network for Earthquake Magnitude Prediction. Elsevier Neural Networks, 22, 1018-1024.

http://dx.doi.org/10.1016/j.neunet.2009.05.003

[5] Sawant, S.S. and Topannavar, P.S. (2015) Introduction to Probabilistic Neural NetworkUsed for Image Classifications. International Journal of Advanced Research in Computer Science \& Software Engineering, 5.

[6] Marco-Detchart, C., Cerron, J., De Miguel, L., Lopez-Molina, C., Bustince, H. and Galar, M. (2016) A Framework for Radial Data Comparison and Its Application to Fingerprint Analysis. Applied Soft Computing, 46, 246-259. http://dx.doi.org/10.1016/j.asoc.2016.05.003

[7] Malhotra, R. (2016) An Empirical Framework for Defect Prediction Using Machine Learning Techniques with Android Software. Applied Soft Computing, In Press.

http://dx.doi.org/10.1016/j.asoc.2016.04.032

[8] Raghavendra, U., Rajendra Acharya, U., Fujita, H., Gudigar, A., Tan, J.H. and Chokkadi, S. (2016) Application of Gabor Wavelet and Locality Sensitive Discriminant Analysis for Automated Identification of Breast Cancer Using Digitized Mammogram Images. Applied Soft Computing, 46, 151-161. http://dx.doi.org/10.1016/j.asoc.2016.04.036 
[9] Vats, E. and Chan, C.S. (2016) Early Detection of Human Actions-A Hybrid Approach. Applied Soft Computing, 46, 953-966. http://dx.doi.org/10.1016/j.asoc.2015.11.007

[10] Bhaumik, H., Bhattacharyya, S., Nath, M.D. and Chakrabory, S. (2016) Hybrid Soft Computing Approaches to Content Based Video Retrieval: A Brief Review. Applied Soft Computing, 46, 1008-1029. http://dx.doi.org/10.1016/j.asoc.2016.03.022

[11] Chagas, S.H., Martins, J.B. and de Oliveria, L.L. (2012) An Approach to Localization Scheme of wireless Sensor Networks Based on Artificial Neural Networks and Genetic Algorithms. 2012 IEEE 10 th International New Circuits and Systems Conference (NEWCAS), 17-20 June 2012, 137-140. http://dx.doi.org/10.1109/NEWCAS.2012.6328975

[12] Wang, H.G., Li, G.L., Ma, Z.H. and Li, X.L. (2012) Application of Neural Networks to Image Recognition of Plant Diseases. 2012 International Conference on Systems and Informatics (ICSAI), Yantai, 19-20 May 2012, 2159-2164.

http://dx.doi.org/10.1109/ICSAI.2012.6223479

[13] Saroha, S. and Aggarwal, S.K. (2014) Multi Step Ahead Forecasting of Wind Power by Different Class of Neural Networks. 2014 Recent Advances in Engineering and Computational Sciences (RAECS), Chandigarh, 6-8 March 2014, 1-6.

http://dx.doi.org/10.1109/ICSAI.2012.6223479

[14] Dhaliwal, B.S. and Pattnaik, S.S. (2012) Performance Evaluation of Artificial Neural Networks in Microstrip Fractal Antenna Parameter Estimation. 2012 IEEE International Conference on Communication Systems (ICCS), Singapore, 21-23 November 2012, 135-139. http://dx.doi.org/10.1109/ICCS.2012.6406124

[15] Ni, Q.K., Guo, C. and Yang, J. (2012) Research of Face Image Recognition Based on Probabilistic Neural Networks. 2012 24th Chinese Control and Decision Conference (CCDC), Taiyuan, 23-25 May 2012, 3885-3888. http://dx.doi.org/10.1109/CCDC.2012.6243102

[16] Xu, X., Shan, D., Wang, G. and Jiang, X. (2016) Multimodal Medical Image Fusion Using PCNN Optimized by the QPSO Algorithm. Applied Soft Computing, 46, 588-595. http://dx.doi.org/10.1016/j.asoc.2016.03.028

[17] Mosavi, M.R. (2007) GPS Receivers Timing Data Processing Using Neural Networks: Optimal Estimation and Errors Modeling. International Journal of Neural Systems, 17, 383393. http://dx.doi.org/10.1142/S0129065707001226

[18] Adeli, H. (2001) Neural Networks in Civil Engineering: 1989-2000. Computer-Aided Civil and Infrastructure Engineering, 16, 126-142. http://dx.doi.org/10.1111/0885-9507.00219

[19] Christodoulou, M.A. and Kontogeorgou, C. (2008) Collision Avoidance in Commercial Aircraft Free Flight, via Neural Networks and Non-Linear Programming. International Journal of Neural Systems, 18, 371-387. http://dx.doi.org/10.1142/S0129065708001658

[20] Adeli, H. and Panakkat, A. (2009) A Probabilistic Neural Network for Earthquake Magnitude Prediction. Neural Networks, 22, 1018-1024. http://dx.doi.org/10.1016/j.neunet.2009.05.003

[21] Astuti, W., Akmeliawatim, R., Sediono, W. and Salami, M.J.E. (2014) Hybrid Technique Using Singular Value Decomposition (SVD) and Support Vector Machine (SVM) Approach for Earthquake Prediction. IEEE Journal of Selected Topics in Applied Earth Observations and Remote Sensing, 7, 1719-1728.

http://dx.doi.org/10.1109/ISTARS.2014.2321972

[22] Dutta, P.K., Mishra, O.P. and Naskar, M.K. (2013) Evaluation of Seismogenesis Behavior in Himalayan Belt Using Data Mining Tools for Forecasting. Central European Journal of Geosciences, 5, 236-253. http://dx.doi.org/10.2478/s13533-012-0127-6

[23] Kulahci, F., Inceoz, M., Dogru, M., Aksoy, E. and Baykara, O. (2009) Artificial Neural Net- 
work Model for Earthquake Prediction with Radon Monitoring. Applied Radiation and Isotopes, 67, 212-219. http://dx.doi.org/10.1016/j.apradiso.2008.08.003

[24] Phili, G., Bhakuni, S.S., Suresh, N. and Virdi, N.S. (2014) Late Pleistocene Faulting along the Growing Janauri Anticline and Seismic Potential in the North-Western Frontal Himalaya, India. Himalayan Geology, 35, 89-96.

[25] Pandey, P. and Pandey, A.K. (2004) Soft Sediment Deformation Features in the Meizoseismal Region of 1999-Chamoli earthquake of Garhwal Himalaya and Their Significance. Himalayan Geology, 25, 79-87.

[26] Gutenberg, B. and Richter, C.F. (1956) Earthquake Magnitude, Intensity, Energy and Acceleration. Bulletin of the Seismological Society of America, 46, 105-146.

[27] Gutenberg, B. and Richter, C.F. (1944) Frequency of Earthquakes in California. Bulletin of the Seismological Society of America, 34, 185-188.

[28] Bayrak, Y., Yilmazturk, A. and Ozturk, S. (2002) Lateral Variation of the Modal (a/b) Values for the Different Regions of the World. Journal of Geodynamics, 34, 653-666. http://dx.doi.org/10.1016/S0264-3707(02)00037-6

[29] Volant, P., Grasso, J.-R., Chatelain, J.-L. and Frogneux, M. (1992) B-Value, Aseismic Deformation and Brittle Failure within an Isolated Geological Object: Evidences from a Dome Structure Loaded by Fluid Extraction. Geophysical Research Letters, 19, 1149-1152. http://dx.doi.org/10.1029/92GL01074

[30] Wiemer, S. (2001) A Software Package to Analyze Seismicity: ZMAP. Seismological Research Letters, 72, 373-382. http://dx.doi.org/10.1785/gssrl.72.3.373

[31] AL-Heety, E.A.M. (2011) Variation of b-Value in the Earthquake Frequency-Magnitude Distribution with Depth in the Intraplate Regions. International Journal of Basic \& Applied Sciences, 11, 29-37.

[32] Tsompanakis, Y., Lagaros, N.D. and Stavroulakis, G.E. (2008) Soft Computing Techniques in Parameter Identification and Probabilistic Seismic Analysis of Structures. Science Direct, Advances in Engineering Software, 39, 612-624.

http://dx.doi.org/10.1016/j.advengsoft.2007.06.004

\section{Submit or recommend next manuscript to SCIRP and we will provide best service for you:}

Accepting pre-submission inquiries through Email, Facebook, LinkedIn, Twitter, etc.

A wide selection of journals (inclusive of 9 subjects, more than 200 journals)

Providing 24-hour high-quality service

User-friendly online submission system

Fair and swift peer-review system

Efficient typesetting and proofreading procedure

Display of the result of downloads and visits, as well as the number of cited articles

Maximum dissemination of your research work

Submit your manuscript at: http://papersubmission.scirp.org/ 